\title{
Role and Effectiveness of Amlodipine (Calcium Channel Blocker) in Expulsion of Ureteric Calculi
}

\author{
H K Garg ${ }^{1 *}$, Ihsanullah Khan ${ }^{2}$ \\ ${ }^{1 *}$ Professor, Department of Pharmacology, Gulf Medical University, Ajman, United Arab emirates. \\ 2Professor \& HOD Urology, Gulf Medical College (GMC), Ajman, United Arab Emirates.
}

\begin{abstract}
Introduction: Urinary stones are being treated with calcium channel blockers (CCBs) such as Nifedipine. It loosens ureter muscles, thus facilitating expulsion of ureteric calculus. We decided to check whether Amlodipine, being safer and longer acting, can replace Nifedipine or not.

Materials and Methods: 120 patients above 18 years, both sexes, with confirmed ureteric calculi, were divided into a study group and control group. Amlodipine (CCB) and Loxoprofen (NSAID) were administered to study group, while the control group patients were kept on the non - steroidal antiinflammatory (NSAID) only. The patients were followed up for 3 months for noting expulsion of ureter stone. Results were tabulated and analysed using SPSS 21 software, with Z test for proportion.

Results: Expulsion rate of ureteric calculi was significantly higher and achieved much earlier in the study group as compared to the control group ( $p<0.001)$. Females showed a better expulsion response as compared to males $(p<0.05)$

Conclusion: Among calcium channel blockers, Amlodipine is
\end{abstract}

\section{INTRODUCTION}

Urinary stones are quite commonly reported in Urology OPD and emergency. Various options are available for surgical treatment of stones that includes ${ }^{1}$ :

- $\quad$ Shock Wave Lithotripsy (ESWL)

- Ureteroscopy (URS)

- Percutaneous nephrolithotomy (PNL)

- Open Surgery

- All the above surgical methods are painful, inconvenient, expensive and relented by the patient.

Rationale

Being non - invasive, Medical management is usually the preferable treatment option as compared to surgery.

Calcium channel blockers are safer option in comparison to diuretics and steroids, which may cause many adverse effects such as electrolyte, sugar, uric acid, lipid profile disturbances ${ }^{2,3}$.

Reports are available in literature regarding effectiveness of calcium channel blockers, such as Nifedipine, but Nifedipine, being short acting, causes tachycardia and is dangerous in cardiac patients. Amlodipine being long acting, seems to be safer ${ }^{4}$ and this is to be verified in our patients. more effective, safer and longer - acting as compared to Nifedipine, which may cause serious ADRs, especially in cardiac patients and has been banned in many countries as well.

Key Words: Amlodipine, Expulsion, Ureteric stone.

\section{*Correspondence to:}

Dr. H K Garg,

Professor, Department of Pharmacology,

Gulf medical university, Ajman, United Arab emirates.

Article History:

Received: 23-08-2016, Revised: 02-09-2016, Accepted: 10-09-2016

\begin{tabular}{|l|c|}
\hline \multicolumn{2}{|c|}{ Access this article online } \\
\hline Website: & Quick Response code \\
www.jmm.com & \\
\hline DOl: & \\
10.21276/jmrp.2016.2.5.034 & \\
\hline
\end{tabular}

No such study using Amlodipine has been taken up in at least UAE, for an important ailment like ureteric calculus.

\section{OBJECTIVE}

To verify the effectiveness of calcium channel blockers (Amlodipine) in expelling ureteric calculi in UAE patients. In most studies around the world, Nifedipine has been used to relax ureter. Hardly any research has been carried out with Amlodipine till now.

\section{PATIENTS AND METHODS}

Study settings

Department of Urology,GMC Hospital \& Research Centre, Ajman, United Arab Emirates (UAE)

Study population

All Patients both male and female, visiting Department of Urology GMC Hospital and Research Centre -Ajman, UAE.

\section{Research design}

A cross sectional prospective study was carried out in patients of both sexes, with ureteric calculi reporting to urology OPD \& 
Emergency room of Gulf medical University, GMC hospital, Ajman, UAE. This was an open label research design in which the patients were in full knowledge of the medication being provided. Inclusion Criteria ${ }^{5}$

- $\quad$ All patients (males as well as females) above the age of 18 years presenting with a ureteric stone of size ranging from $0.5 \mathrm{~cm}$ to $1 \mathrm{~cm}$.

- All such stones occupying the upper, middle and lower segments of the ureter.

\section{Exclusion Criteria $^{5}$}

- Patients already having been operated for ureteric stone.

- Patients less than 18 years of age.

- Patients already on antihypertensive medications excluding Calcium channel blockers (CCBs).

- Patients intolerant to Amlodipine.

- $\quad$ Stone size larger than $1 \mathrm{~cm}$.

- Patients with renal failure, serum creatinine $>3 \mathrm{mg} / \mathrm{dl}$

- Patients with risk factors for urosepsis, such as prolonged obstruction and associated infection.

\section{Sample size}

A total of 120 patients of both sexes (60 patients each, in the study as well as the control groups). The sample size has been calculated after taking into consideration the following facts:

- According to available clinical research reports, about $68 \%$ patients have spontaneous ureteric stone expulsion. However, $77 \%$ expulsion rate has been recorded with addition of Nifedipine ${ }^{14}$.

- With a minimum sample size of $60+60$ patients, the difference in these figures becomes statistically significant.

- Considering the power of the study as $80 \%$, the sample size is appropriate.

\section{Duration of study}

6 months from the date of approval of the proposal from the ethical committee of GMC hospital and research center.

\section{Study instrument \& validation procedure}

The study was carried out with the help of:

- Diagnosis by history and investigations

- Treatment with \& without Amlodipine (a calcium channel blocker).

No questionnaire was used in this study. The investigation instruments such as CT scan \& ultrasound etc. are already considered as validated. A clinical data information sheet was used to fill relevant clinical details of the patient.

\section{Ethical issues}

All patients were informed in detail about this study and their role; an informed consent was obtained. Gulf medical University Ethical Committee clearance was obtained prior to the study.

\section{Methodology 6}

Diagnosis was made based on history and radiological investigations, namely, ultrasound \& spiral C-T Scan of the abdomen. Other urinary \& hematological investigations such as routine urine examination, kidney function tests and blood sugar were also performed. Patients were randomly divided into two groups:

- Group A (study group on Loxoprofen (NSAID)+ Amlodipine (calcium channel blocker) and

- Group B (control group on NSAID Loxoprofen alone).
Group A patients were prescribed tablets of Amlodipine and Loxoprofen (NSAIDs).

Group B subjects were prescribed. Loxoprofen (NSAIDs) only. Tablet Rowatinex which contains olive oil was added to both groups to add bulk to the treatment prescription and patient satisfaction.

Doses of these drugs were as per requirement, literature ${ }^{6}$, manufacturer directives and clinical judgment. Amlodipine dose ranged from 5 to10 $\mathrm{mg}$. Loxoprofen dose was between180-360 $\mathrm{mg}$ (3-6 tablets per day), as per the formulation and requirement. Rowatinex dose varied between 1- 2 tablet three times a day.

Patients were followed up in OPD for 3 months on fortnightly basis for stone expulsion, which was monitored by history, ultrasound examination, $X$ rays and spiral $C-T$ during and at the end of the study. Imaging modalities like Ultrasound, X-ray and CT scan were used electively according to situation and requirement to reduce cost of treatment.

Surgical intervention was advised in patients with recurrent attacks of colic, urinary tract infection and unchanging location of stone along with increasing hydronephrosis ${ }^{8}$. New patients were included time and again, to compensate for patients who left study.

\section{Feasibility of the proposed research}

This study was quite convenient to carry out, because the patients were being treated by the investigators. The investigations were carried out in the same hospital $(\mathrm{GMCH})$. Almost all of our patients had health insurance and these insurance companies bore all the expenses for diagnosis and treatment .

\section{Data analysis\& storage}

The data were analyzed using SPSS 21 software, with the help of $Z$ test for proportion.

Simple percentage calculations were done in an excel sheet master chart.

Help of a senior statistician was taken for data analysis.

Time line

Patients of ureteric calculi suitable for study reporting at Urology OPD of GMC hospital, Ajman, were included in this study. About 6 months were spent in collecting and processing data from these patients and also for follow- up.

\section{RESULTS}

Equal number of males and female patients of ureteric calculus were included in the study in both, study as well as control groups. Maximum number of patients belonged to 18 to 30 years age group, which is significantly higher number than in older patients $(p<0.001)$. Minimum patients were in $50+$ age group which is statistically significant $(p<0.001)$. Incidence of ureteric calculus was not significantly different in both sexes (Table 1) in both the groups.

Average stone expulsion in females was achieved much earlier $(\approx$ 15 days vs. 21 days; $p<0.001)$ and to a higher extent $(90 \%$ vs. $80 \% ; p<0.05)$ as compared to the males which is statistically significant.

The control group patients were not able to expel ureteric stones before 3 months. Only 5 to 6 percent patients experienced spontaneous stone expulsion. On the contrary, $85 \%$ patients of study group successfully passed out their ureteric stones, in less than 3 weeks. This contrast is highly significant $(p<0.001)$ 
H K Garg \& Ihsanullah Khan. Amlodipine in Expulsion of Ureteric Calculi

Table 1: Age and gender - wise distribution of ureteric calculus patients

\begin{tabular}{lcccccccc}
\hline & \multicolumn{8}{c}{ Number of patients studied (n=120) } \\
\cline { 2 - 10 } Age group & Male & Study group [A] $(\mathbf{n}=\mathbf{6 0})$ & \multicolumn{5}{c}{ Control group [B] $(\mathbf{n}=\mathbf{6 0})$} \\
$\mathbf{1 8}-\mathbf{3 0}$ & 15 & 25 & 14 & 23.33 & 16 & 26.66 & 14 & 23.33 \\
$\mathbf{3 1}-\mathbf{4 0}$ & 10 & 16.66 & 10 & 16.66 & 9 & 15 & 11 & 18.33 \\
$\mathbf{4 0}-\mathbf{5 0}$ & 4 & 6.66 & 4 & 6.66 & 3 & 5 & 3 & 5 \\
$\mathbf{5 1}-\mathbf{6 0}$ & 1 & 1.66 & 2 & 3.33 & 1 & 1.66 & 2 & 3.33 \\
$>\mathbf{6 1}$ & - & & - & & 1 & 1.66 & - & \\
\hline
\end{tabular}

Table 2: Time taken for Expulsion of ureteric stone in both sexes

\begin{tabular}{lcccc}
\hline & \multicolumn{3}{c}{ Time and \% of expulsion of ureteric stone (days) } \\
\cline { 2 - 5 } & \multicolumn{2}{c}{ Study group $[\mathbf{A}](\mathrm{n}=\mathbf{3 0})$} & \multicolumn{2}{c}{ Control group $[\mathrm{B}](\mathrm{n}=\mathbf{3 0})$} \\
Days & $\%$ success & Days & $\%$ success \\
Males $(\mathrm{n}=24)$ & $20.68 \pm 2.46$ & 80 & $>90$ & 5 \\
Females $(\mathrm{n}=27)$ & $14.76 \pm 2.38$ & 90 & $>90$ & 6 \\
\hline
\end{tabular}

\section{DISCUSSION}

Ureteric stones are reported usually at emergency room rather than in OPDs. Ureter has to be relaxed and the stone needs to be flushed out by higher water intake. Since the stone size was less than $1 \mathrm{~cm}$ in all patients, medical management was preferred, rather than surgical ${ }^{7}$.

Calcium channels are much safer as compared to diuretics ${ }^{9}$. Till now, Nifedipine has been used by urologists in most countries ${ }^{10-13}$. But, because of tachycardia caused by it, many cardiac patients died and it has been banned by many countries ${ }^{4}$. Amlodipine is a long acting dihydropyridine (DHP) class calcium channel blocker which relaxes smooth muscles, and is widely used as an antihypertensive drug 4 . We just thought of trying out Amlodipine and the results are highly optimistic. About $85 \%$ success was achieved with Amlodipine, within 3 weeks.

\section{CONCLUSION}

We are probably the first researchers to have used Amlodipine for expelling ureteric calculi. Being safer, Amlodipine should be preferred to Nifedipine in ureteric calculus patients.

\section{REFERENCES}

1. C. Türk (chair), T. Knoll (vice-chair), A. Petrik, et al: Guidelines on Urolithiasis. European Association of Urology.2013; 26-33.

2. Hollingsworth JM, Rogers MA, Kaufman SR, Bradford TJ, Saint $\mathrm{S}$, Wei JT, et al. Medical therapy to facilitate urinary stone passage: A meta-analysis. Lancet. 2006; 368:1171-9.

3. Davenport K, Timoney AG, Keeley FX. A comparative in vitro study to determine the beneficial effect of calcium-channel and alpha 1adrenoceptor antagonism on human ureteric activity. BJU Int. 2006; 98:651-5.

4. Tripathi KD, Essentials of medical pharmacology; JP brothers; 7th Ed, 2007; 549.

5. Hollingsworth JM, Rogers MA, Kaufman SR, Bradford TJ, Saint $\mathrm{S}$, Wei JT, et al. Medical therapy to facilitate urinary stone passage: A meta-analysis. Lancet.2006; 368:1171-9. [PubMed] 6. Saita A, Bonaccorsi A, Marchese F, Condorelli SV, Motta M. Our experience with nifedipine and prednisolone as expulsive therapy for ureteral stones. Urol Int. 2004; 72: 43-5. [Pub Med]
7. Macneil F, Bariol S; Urinary stone disease - assessment and management. Aust Fam. Physician. 2011 Oct; 40(10):772-5.

8. Yun Yan Wang, Jian Quan Hou, Duangai Wen et al; comparative analysis of upper ureteral stones $(15 \mathrm{~mm})$ treated with retroperitoneoscopic ureterolithotomy and ureteroscopic pneumatic lithotripsy: Int. Urolnephrol (2010) 42:897-901.

9. Wolfgram, D. F., Gundu, V., Astor, B. C., \&Jhagroo, R. A. (2013). Hydrochlorothiazide compared to Chlorthalidone in reduction of urinary calcium in patients with kidney stones. Urolithiasis 2013, 41(4), 315-322

10. Gupta A, Aboumarzouk OM, Jefferies MT, Kynaston HG, Datta S. Calcium channel blockers as medical expulsive therapy for ureteric stones (Protocol). Cochrane Database of Systematic Reviews 2014, Issue 7.

11.Hussain, M., Hashmi, A. H., \& Rizvi, S. A. H : Problems and prospects of neglected renal calculi in Pakistan: Can this tragedy be averted? Urology Journal,(2013) 10(2), 848-55.

12. Himesh R. Gandhi and Chandrasekhar Agrawal :The efficacy of Tamsulosin vs. Nifedipine for the medical expulsive therapy of distal ureteric stones: A randomized clinical trial.Arab Journal of Urology. 12/2013; 11(4):405-410.

13.Seitz C, Liatsikos E, Porpiglia F, et al; Medical therapy to facilitate the passage of stones: what is the evidence? Eur Urol. 2009 Sep;56(3):455-71. E pub 2009 Jun 21.

\section{Source of Support: Nil. Conflict of Interest: None Declared. \\ Copyright: (c) the author(s) and publisher. IJMRP is an official publication of Ibn Sina Academy of Medieval Medicine \& Sciences, registered in 2001 under Indian Trusts Act, 1882. \\ This is an open access article distributed under the terms of the Creative Commons Attribution Non-commercial License, which permits unrestricted non-commercial use, distribution, and reproduction in any medium, provided the original work is properly cited.}

Cite this article as: H K Garg, Ihsanullah Khan. Role and Effectiveness of Amlodipine (Calcium Channel Blocker) in Expulsion of Ureteric Calculi. Int J Med Res Prof. 2016; 2(5):16567. 